\title{
Michael Muhr: Hochspannungstechnik - ein Menschenleben lang
}

\section{H. Stigler}

Online publiziert am 15. September 2012

(C) Springer-Verlag 2012

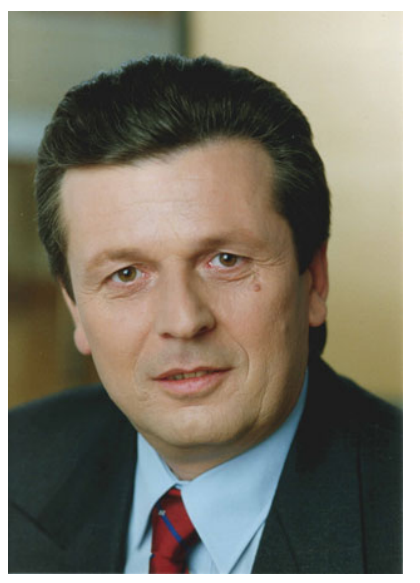

Heinz Stigler
Wie sich die Wurzel des Nachnamens Muhr von der ehemaligen familiären Herkunft vom Mur-Ursprung und damit dem zentralen Fluss der Steirer ableitet, so war unser Emeritus stets ein "gerader" Michael: klar in der Vertretung seiner Meinung, Respektierung der Meinung des anderen, Priorisierung des Miteinander über das Gegeneinander und Akzeptanz getroffener Entscheidungen.

Wenn unser Michael stets die Interessen der Universität und der Fakultät an erste Stelle setzte, so sorgte er sich auch adäquat um das ihm überantwortete Institut für Hochspannungstechnik und Systemmanagement: In selten anzutreffender Weise übergibt er durch eine Großinvestition zeitgleich mit seiner Emeritierung ein wohlbestalltes Haus an den/die Nachfolger/in.

Neben den vielen Funktionen im überindividuellen Dienste an TU Graz und Fakultät hat Michael in allen Berufungskommissionen des „Energie Zentrum Graz” an hervorragender Stelle mitgewirkt und damit für dessen gedeihliche Zusammensetzung und Fortführung des Begonnenen gesorgt.

Durch die Schaffung von Voraussetzungen für den Erfolg der Fakultät hat er sich dauerhafte Verdienste erworben:

- Beitrag zur Beendigung der jahrzehntelang schmerzlich empfundenen räumlichen Zersplitterung der Fakultät und Zusammenführung in der Inffeldgasse

- Konkretisierung der neuen Versuchshalle des Institutes für Elektrische Maschinen

- Initiierung des „Energie Zentrum Graz”

Lieber Michael, anlässlich Deiner Emeritierung sage ich Dir vielen herzlichen Dank für all Dein Engagement und Wirken für die engere und weitere Schicksalsgemeinschaft TU Graz, Fakultät und Energie Zentrum Graz! Gerne füge ich auch an, dass das Dekanat der Fakultät der letzten Jahre durch viele Gespräche mit Dir wesentlich profitierte!

\section{ETIT-Spektabilität und (manchmal) Dean}

Dein Dir aufrichtig verbundener

\section{Heinz Stigler}

Des Menschen Leben währet siebzig Jahre, wenn es hoch kommt sind es achtzig, doch wenn es köstlich war, dann ist es Mühe und Plage gewesen. 